\title{
Burkholderia bacteria use chemotaxis to find social amoeba Dictyostelium discoideum hosts
}

\author{
Longfei Shu $\mathbb{D}^{1} \cdot$ Bojie Zhang $\mathbb{B}^{2} \cdot$ David C. Queller ${ }^{1} \cdot$ Joan E. Strassmann ${ }^{1}$
}

Received: 1 September 2017 / Revised: 5 February 2018 / Accepted: 28 March 2018 / Published online: 24 May 2018

(c) International Society for Microbial Ecology 2018

\begin{abstract}
A key question in cooperation is how to find the right partners and maintain cooperative relationships. This is especially challenging for horizontally transferred bacterial symbionts where relationships must be repeatedly established anew. In the social amoeba Dictyostelium discoideum farming symbiosis, two species of inedible Burkholderia bacteria (Burkholderia agricolaris and Burkholderia hayleyella) initiate stable associations with naive D. discoideum hosts and cause carriage of additional bacterial species. However, it is not clear how the association between D. discoideum and its carried Burkholderia is formed and maintained. Here, we look at precisely how Burkholderia finds its hosts. We found that both species of Burkholderia clones isolated from D. discoideum, but not other tested Burkholderia species, are attracted to D. discoideum supernatant, showing that the association is not simply the result of haphazard engulfment by the amoebas. The chemotactic responses are affected by both partners. We find evidence that $B$. hayleyella prefers $D$. discoideum clones that currently or previously carried Burkholderia, while B. agricolaris does not show this preference. However, we find no evidence of Burkholderia preference for their own host clone or for other hosts of their own species. We further investigate the chemical differences of $D$. discoideum supernatants that might explain the patterns shown above using a mass spectrometry based metabolomics approach. These results show that these bacterial symbionts are able to preferentially find and to some extent choose their unicellular partners. In addition, this study also suggests that bacteria can actively search for and target phagocytic cells, which may help us better understand how bacteria interact with immune systems.
\end{abstract}

\section{Introduction}

Mutualistic cooperation occurs at all levels of life. Cooperators often have mechanisms to find partners and even to choose good partners over bad ones. Finding a partner is an important aspect of mutualistic associations, particularly for the question of specialisation. If partner association is haphazard, or if partner-finding abilities are weak, selection

Subject Categories: Microbe-microbe and microbe-host interactions

Electronic supplementary material The online version of this article (https://doi.org/10.1038/s41396-018-0147-4) contains supplementary material, which is available to authorized users.

Longfei Shu

longfei.shu@wustl.edu

1 Department of Biology, Washington University in St. Louis, St. Louis, MO 63130, USA

2 Department of Chemistry, Washington University in St. Louis, St. Louis, MO 63130, USA for mutualism may be weakened or countered by the need to retain adaptations for surviving and reproducing in the absence of partners. When partner-finding is reliable, partners can more readily evolve to specialise on each other. Mutualistic cooperation can also be favoured by partner choice, which requires partner-finding that is effective enough to offer choices [1]. However, in mutualisms with vertical transmission of symbionts, partner-finding adaptations may not be necessary and could be lost. At this point, specialisation to particular lineages can become extreme.

Partner-finding can have different modalities. For instance, in the pollination systems, plants often use visual and/or olfactory signals to attract pollinators [2, 73]. For mate choice in animals, mate finding can involve visual, olfactory and/or auditory signals in different taxa [3, 4]. For microbes, which lack a sensory nervous system, partnerfinding is often mediated through chemicals either at a distance, such as quorum sensing in bacteria [5], or via contact dependent recognition such as in social amoeba [6] and myxobacteria [7]. 
When bacterial symbionts actively find partners, it is likely to be through chemotaxis. Chemotaxis is the directed movement of cells in a chemical gradient, which plays a major role in many important biological processes $[8,9]$. Multicellular organisms need chemotaxis for various developmental functions [10, 11] (for example, embryology, migration and aggregation) and it is also involved in processes like cancer metastasis [12]. Bacteria use it to search for food, avoid toxins and respond to changing environments [8]. Bacterial chemotaxis can play important roles in symbiotic associations. Several studies have reported evidence of chemotaxis of bacterial symbionts toward multicellular eukaryotic hosts, including animals [13-15], plants [16-19] and fungi [20, 21].

There is little empirical evidence that bacterial chemotaxis is important in symbioses with unicellular protist hosts. Protists are an extremely diverse paraphyletic grouping of generally unicellular eukaryotic organisms that are not animals, plants or fungi [22]. They can interact with bacteria in multiple ways. Some of them are predators of bacteria, others are victims of bacterial pathogens and still others can even form symbiotic interactions [23-28]. However, because of the difficulties in cultivation of protists, as well as the commonness of unculturable bacterial symbionts, experimental studies of symbiotic relationships between protists and bacteria so far have been limited to a few cultured model systems [23, 24, 28-33]. Emerging techniques such as single-cell sequencing could help to discover potential protist-bacteria interactions [34]. Still, little is known about partner attraction and choice in protist-bacteria interactions. Progress is most likely or be made in simple model systems, where the impact of different partners can be understood and manipulated.

The amoeba proto-farming symbiosis with bacteria is a promising system for gaining insight into the question about how cooperation in protist-bacteria interactions forms and is maintained [23, 24, 28, 30, 31, 35]. D. discoideum is a soil-dwelling amoeba that is well known for its unusual life cycle [36]. At the unicellular stage, vegetative cells eat bacteria through phagocytosis and divide through binary fission. When bacterial prey are exhausted, amoebas aggregate to form multicellular migratory slugs, which ultimately become fruiting bodies. About $20 \%$ of the cells die to form a stalk while the rest differentiate into spores in the sorus, which sits atop the stalk [36]. Some wild amoeba clones were collected in association with different bacterial partners that can potentially be used as food and/or weapons $[23,24,28]$. We call these clones farmers because they can seed and defend their crops in new environments [23]. However, farming status is caused by key bacteria associates belonging to the genus Burkholderia [31]. Two clades (now named as $B$. agricolaris and B. hayleyella, and the amoeba clones that are carrying them are called $B$. agricolaris farmers and $B$. hayleyella farmers, respectively) of Burkholderia can initiate a stable association with naive D. discoideum hosts and are found within Dictyostelium cells and spores. They are not good food sources for the amoebas but they benefit the amoebas by causing carriage of additional bacterial species some of which are released to seed new food populations. The Burkholderia presumably benefit by living inside the amoebas and dispersing in amoeba spores. Curing the amoebas of these Burkholderia eliminates this farming trait [31].

Both $B$. agricolaris and $B$. hayleyella can live on their own and can colonize new amoeba clones, indicating they are facultative symbionts, probably with some horizontal transmission. This raises the question that how the association between $D$. discoideum and its carried Burkholderia is formed and maintained. It could be accidental, simply happening when the carried Burkholderia are randomly ingested by the amoeba host. Alternatively, Burkholderia symbionts may be able to preferentially find and choose their social amoeba partners. In this study, we will test these hypotheses. Specifically, we conducted chemotaxis and metabolomics experiments to answer the following questions: (1) Are Burkholderia symbionts attracted to their amoeba hosts? (2) How specific are these choices? and (3) What small molecules are involved in these choices?

\section{Materials and methods}

\section{Wild $D$. discoideum clones, media and culture conditions}

This study used wild $D$. discoideum clones $(N=15)$ collected at Mountain Lake Biological Station in Virginia (clones with a QS designation, $37^{\circ} 21^{\prime} \mathrm{N}, 80^{\circ} 31^{\prime} \mathrm{W}$ ) and Little Butt's Gap, North Carolina (clones with a NC designation, $35^{\circ} 46^{\prime} \mathrm{N}, 82^{\circ} 20^{\prime} \mathrm{W}$ ). We cured farmer $D$. discoideum clones by treating them with tetracycline [31]. We grew $D$. discoideum from previously frozen spores on $\mathrm{SM} / 5$ agar plates $(2 \mathrm{~g}$ glucose, $2 \mathrm{~g}$ BactoPeptone (Oxoid), $2 \mathrm{~g}$ yeast extract (Oxoid), $0.2 \mathrm{~g} \mathrm{MgCl}_{2}, 1.9 \mathrm{~g} \mathrm{KH}_{2} \mathrm{PO}_{4}, 1 \mathrm{~g}$ $\mathrm{K}_{2} \mathrm{HPO}_{4}$ and $15 \mathrm{~g}$ agar per liter) with food bacterium Klebsiella pneumoniae at room temperature $\left(21^{\circ} \mathrm{C}\right)$. Specific clones used in this study are listed in Table S1.

\section{Burkholderia isolates from wild $D$. discoideum farmers}

This experiment used carried Burkholderia isolates $(N=6)$ described in previous studies [31]. We spotted the sorus contents of farmer clones individually on SM/5 agar plates and assessed bacterial growth after seven days at room temperature. We isolated single colonies from these spots 


\section{D. discoideum hosts}
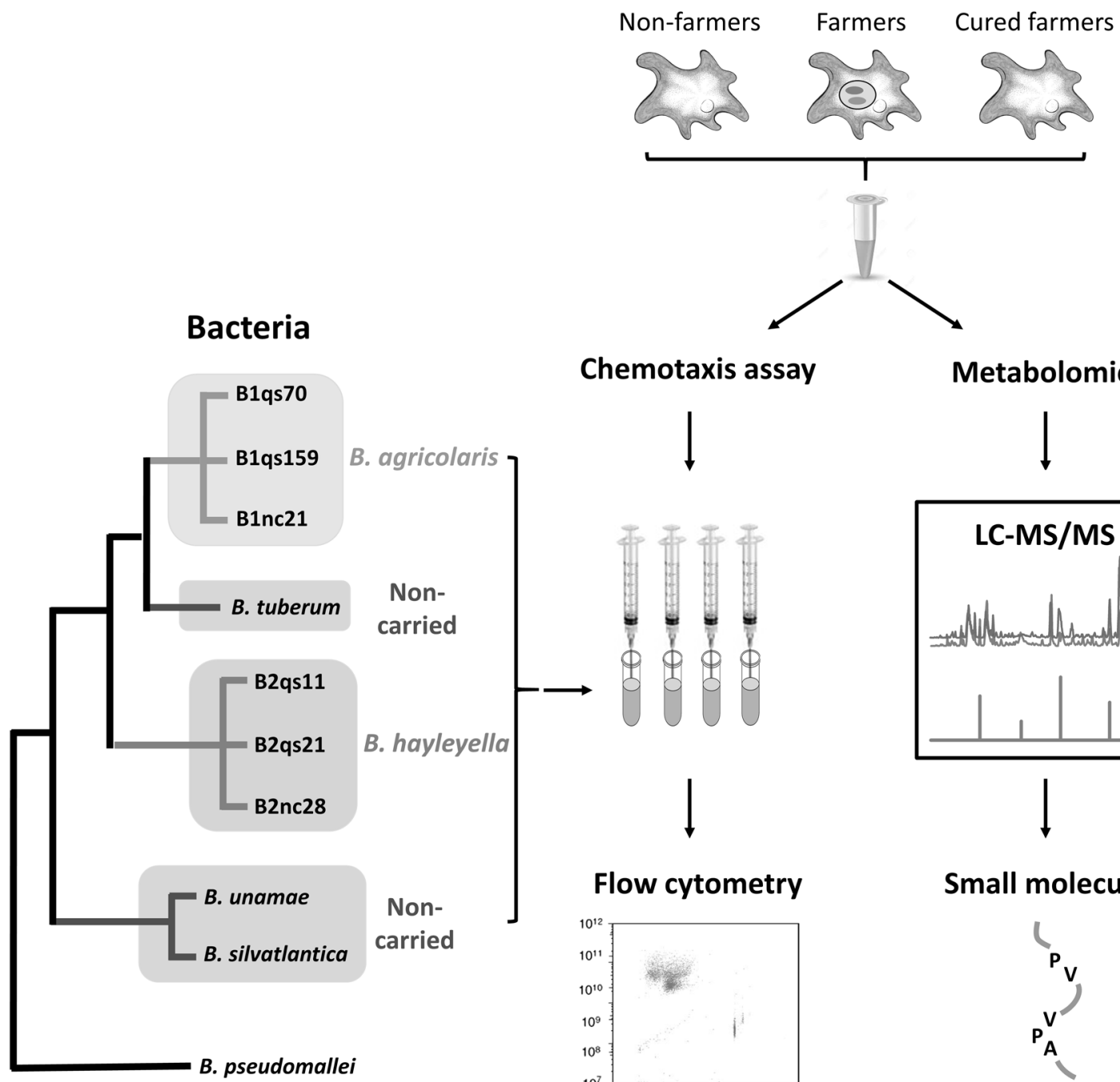

Chemotaxis assay
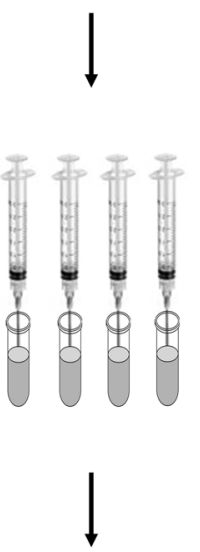

Flow cytometry

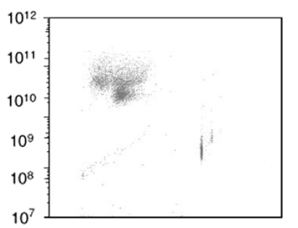

pers. comm.). We used amoeba supernatants as chemoattractants and counted the number of bacteria in the syringe using flow cytometry. We further analysed the amoeba supernatants using a metabolomics approach. We identified the potential attracting molecules using liquid chromatography/mass spectrometry (LC-MS/MS)

\section{Metabolomics}

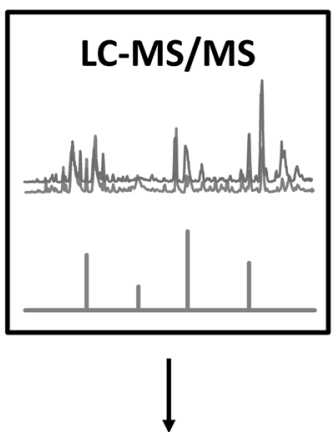

Small molecules

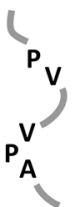

by restreaking bacteria on SM/5 agar medium up to three times. We then identified clones via $16 \mathrm{~s}$ rRNA gene sequencing [23, 31]. Phylogenetic analyses show these carried Burkholderia belong to two clades (now named as $B$. agricolaris and $B$. hayleyella) [31]. We tested three $B$. agricolaris (B1qs70, B1qs159 and B1nc21) and three $B$. hayleyella (B2qs11, B2qs21 and B2nc28) Burkholderia clones. We also used three non-carried Burkholderia species (Burkholderia unamae, Burkholderia tuberum and Burkholderia silvatlantica, [74]) to see if attraction to $D$. discoideum is specific to the carried species (Fig. 1). Specific isolates used in this study are listed in Table S1. Recently, it has been proposed to split the genus

Burkholderia into two genera according to phylogenetic clustering: (1) a genus retaining this name (mostly animal and plant pathogens) and (2) the genus Paraburkholderia (environmental bacteria) [37]. However, there are debates about this reclassification [38]. Therefore, we continue to use the original (Burkholderia) names for our species.

\section{Motility test of Burkholderia isolates}

Motility is the ability to move spontaneously and actively. We tested the motility of carried Burkholderia isolates $(N=$ 6) using swim and swarm plate assays according to procedures described earlier [39, 40]. For the swim assay, we 
prepared and used the swim plates (SM/5 supplemented with $0.3 \%$ agar) the same day. For each isolate, we prepared the bacteria by starting from the frozen clonal isolate and then incubating at room temperature $\left(21^{\circ} \mathrm{C}\right)$ until stationary phase was reached. We then inoculated $10 \mu \mathrm{L}$ of bacteria suspensions (optical density 2.0) at the centre of the plates, stabbing the pipette tip into the agar during inoculation [39]. For the swarm assay, we also prepared and used the swarm (SM/5 supplemented with $0.8 \%$ agar) plates the same day. We inoculated $10 \mu \mathrm{L}$ of bacteria suspensions (optical density 2.0) at the centre of the plates with the pipette tip close to the agar surface during inoculation [40]. We inoculated all plates for $48 \mathrm{~h}$ at $30^{\circ} \mathrm{C}$ and plates were kept upright and not inverted. At $48 \mathrm{~h}$ we measured the diameter of the colonial growth. We used non-motile (K. pneumoniae) and three motile (Burkholderia unamae, Burkholderia tuberum and Burkholderia silvatlantica) controls [41-43]. We did three replicates for each strain.

\section{Preparation of supernatants with potential $D$. discoideum chemoattractants}

We prepared $D$. discoideum supernatants $(N=15)$ from log-growth amoebas for the chemotaxis experiment. We prepared log-growth amoebas by plating $2 \times 10^{5}$ spores in $200 \mu \mathrm{K}$. pneumoniae suspension in starvation buffer $(2.25$ $\mathrm{g} \mathrm{KH}_{2} \mathrm{PO}_{4}$ and $0.67 \mathrm{~g} \mathrm{~K}_{2} \mathrm{HPO}_{4}$ per liter $\mathrm{H}_{2} \mathrm{O}$ ) at an $\mathrm{OD}$ of 1.5 on $\mathrm{SM} / 5$ plates. We have previously determined that spore germination and amoeba log growth occurs at about 32-36 $\mathrm{h}$ after plating [24]. When clones reached log-phase growth, we collected amoebas using ice-cold starvation buffer and centrifuged the collected amoebas/bacterial suspension at $1500 \mathrm{~g}$ for $3 \mathrm{~min}$ to wash the amoebas clean of bacteria. We washed the pelleted amoebas in an excess volume of ice-cold starvation buffer three to four times to remove remaining bacteria.

For the experiment, we placed $10^{8}$ amoebas in a $15-\mathrm{ml}$ conical tube containing starvation buffer and we used a New Brunswick C1 Platform Shaker set at speed 25 to gently rotate the amoeba suspension for $8 \mathrm{~h}$ at $21^{\circ} \mathrm{C}$. At $8 \mathrm{~h}$, we isolated the supernatant from the amoebas by centrifuging the amoeba suspension in an Eppendorf Centrifuge $5804 \mathrm{R}$ at $1500 \mathrm{~g}$ for $3 \mathrm{~min}$. We further isolated the supernatants in an Eppendorf Centrifuge $5804 \mathrm{R}$ at $12,000 \mathrm{~g}$ for $30 \mathrm{~min}$ at $4^{\circ} \mathrm{C}$. We decanted the supernatant to a fresh, sterile conical tube and placed the tube at $4{ }^{\circ} \mathrm{C}$. We then filtered the supernatants through a $0.2-\mathrm{mm}$ sterile syringe filter (Millipore) and kept them at $4{ }^{\circ} \mathrm{C}$ until experimental set-up. To test if those amoebas were still viable after $8 \mathrm{~h}$, we plated the amoebas on SM/5 plate to see if they can aggregate and form fruiting bodies. All tested D. discoideum clones were still able to form fruiting bodies.

\section{Capillary chemotaxis assay for carried Burkholderia}

To investigate the chemotactic responses of carried Burkholderia $(N=6)$ in response to amoeba supernatants $(N=$ 15 ), we used a capillary assay described previously [44]. We used an Eppendorf tube as a chamber for holding $200 \mu \mathrm{l}$ of bacterial suspension (OD 2.5) in starvation buffer. We used a 2-cm 25-gauge needle (Becton Dickinson) as the chemotaxis capillary and attached it to a $1-\mathrm{mL}$ tuberculin syringe (Becton Dickinson) containing a $100 \mu \mathrm{l}$ of amoeba supernatant. After $4 \mathrm{~h}$ incubation at room temperature, we removed the needle syringe from the bacterial suspension and collected the contents. We measured the accumulation of bacteria in the capillaries using flow cytometry. We diluted the bacterial contents to a final volume of $1.0 \mathrm{~mL}$. For each assay, we added $1 \mu \mathrm{L}$ of $\mathrm{SYTO}^{\circledR} \mathrm{BC}^{\mathrm{B}}$ bacteria stain (Component A) and $10 \mu \mathrm{L}$ of microsphere suspension (Component B) into the diluted bacteria. The mixture was incubated at room temperature for 10 minutes. We then assayed the coloured bacteria in a flow cytometer equipped with a laser emitting at $488 \mathrm{~nm}$. Fluorescence is collected in the fluorescein channel. The forward scatter and fluorescence were collected with logarithmic signal amplification. We calculated the number of bacteria using the number of microspheres $\left(10^{6}\right.$ per $\left.\mathrm{mL}\right)$ as a standard. There are three biological replicates for each experimental unit and each replicate was measured three times. This design resulted in a total of 6 (carried Burkholderia) $\times 16$ (amoeba supernatants and blank control) $\times 3$ (biological replicates) $\times 3$ (technical replicates for bacterial counting $)=864$ experimental units for the chemotaxis assay. This means there are 96 host-Burkholderia combinations, and for each combination there are three biological and three technical replicates. We used the mean of each host-Burkholderia combination for further analysis.

\section{Host preferences of Burkholderia}

Next, we wanted to know how specific these chemotactic responses are and whether farmer-associated Burkholderia would prefer their original farmer hosts. We investigated host preferences at both species and clone levels. We used the same chemotaxis data set $(N=96)$ for this purpose. However, we analysed and plotted B. agricolaris and $B$. hayleyella separately.

To investigate if carried Burkholderia are more attracted to host supernatants than non-carried Burkholderia, we used three non-carried Burkholderia species (B. unamae, B. tuberum and $B$. silvatlantica) to see if attraction to $D$. discoideum is specific to the carried species. We used the same capillary assay describes above. 


\section{Burkholderia-Burkholderia attractions}

To investigate the potential chemotactic responses of carried Burkholderia $(N=6)$ in response to their own secretions $(N=6)$, we used the same capillary assay described above, except that amoeba supernatants were replaced by Burkholderia supernatants. To prepare Burkholderia supernatants, we placed $8 \mathrm{ml}$ of bacterial suspension (OD $1.5,10^{9}$ cells) in a $15-\mathrm{ml}$ conical tube containing starvation buffer and we used a New Brunswick C1 Platform Shaker set at speed 25 to gently rotate the Burkholderia suspension for $8 \mathrm{~h}$ at $21^{\circ} \mathrm{C}$. We isolated the supernatants in an Eppendorf Centrifuge $5804 \mathrm{R}$ at $12,000 \mathrm{~g}$ for $30 \mathrm{~min}$ at $4{ }^{\circ} \mathrm{C}$. We then filtered the supernatants through a $0.2-\mathrm{mm}$ sterile syringe filter (Millipore) and use them for a modified capillary assay (see above session). This design resulted in a total of 6 (Burkholderia) $\times 7$ (Burkholderia supernatants and blank) $\times 3$ (replicates) $=126$ experimental units.

\section{Identification of potential attracting molecules using LC-MS/MS}

We identified the potential attracting molecules in all 15 amoeba supernatants using liquid chromatography-tandem mass spectrometry (LC-MS/MS). We performed LC-MS/ MS experiments on the Thermo Dionex UltiMate 3000 HPLC (Waltham, MA) and the Thermo Q Exactive Plus mass spectrometer (Waltham, MA). We centrifuged the samples at $8000 \mathrm{rcf}$ for $3 \mathrm{~min}$ prior to analysis. We loaded 5 $\mu \mathrm{L}$ from each sample to the Thermo Acclaim Pepmap 100 C18 column (Waltham, MA) by solvent A at $5 \mu \mathrm{L} / \mathrm{min}$ flow rate. After that, the samples were eluted by a linear gradient at $500 \mathrm{~nL} / \mathrm{min}$ and further separated by a homemade column. The column was $100-\mu \mathrm{m}$-inner-diameter and $12-\mathrm{cm}-$ length silica tubing packed with Magic C18 AQ reversed phase material. The gradient was increased from $98 \%$ solvent $\mathrm{A}$ and $2 \%$ solvent $\mathrm{B}$ to $2 \% \mathrm{~A}$ and $98 \% \mathrm{~B}$ in $50 \mathrm{~min}$. Solvent A was $0.1 \%$ formic acid in water and solvent B was $0.1 \%$ formic acid in $80 \%$ acetonitrile and $20 \%$ water (v:v). The analyte was ionised and introduced into the mass spectrometer by the Thermo Nanospray Flex Ion Source (Waltham, MA) in positive mode. Each amoeba supernatant was run once due to logistic reason, resulting a total of 15 data sets for 15 amoeba supernatants.

\section{Metabolomics analysis}

Data from LC-MS/MS based untargeted metabolomic experiments are highly complex, therefore we subjected the results to analysis by XCMS Online [45-47]. The data files were converted to mzXML format by MSConvert with peak picking filter enabled. The parameters were as follows: centWave for feature detection, $\Delta \mathrm{m} / \mathrm{z}=5 \mathrm{ppm}$, min peak width $=5 \mathrm{~s}$, max peak width $=40 \mathrm{~s}$; obiwarp for retention time correction with profStep $=1 ; \operatorname{minfrac}=0.5$, bw $=10$ and mzwid $=0.025$ for chromatographic alignment.

Compounds of interest can sometimes be identified from the differences between two groups [45]. Because the strongest group differences from our capillary assays was between supernatants from $D$. discoideum (farmers) carrying Burkholderia vs. D. discoideum not carrying Burkholderia (non-farmers and cured farmers), we performed a two-group comparison between $D$. discoideum carrying (six farmers) and not carrying (six cured farmers and three nonfarmers) Burkholderia by processing pairwise jobs at XCMS Online [45]. We selected Mann-Whitney test (with false discovery rate adjusted p-value) for the two-group comparisons at XCMS Online [45]. For the features that are not identified by MS/MS, we identified them by searching their accurate mass in the METLIN database. All candidates have a mass differences less than $5 \mathrm{ppm}$, which is limited by the resolution of the mass spectrometer. Adducts such as $\left[\mathrm{M}+\mathrm{NH}_{4}\right]^{+}$are included, but restricted to the specified charge states of the features. For unknown charge states, both +1 and +2 charges are included.

\section{Statistical analyses}

\section{Partner attraction and choice}

For chemotaxis experiments, the accumulation of Burkholderia in response to the amoebal secretions was expressed in terms of a chemotaxis index. Because tested Burkholderia differ somewhat in their motility (Figure S1), we normalised the chemotaxis index using the motility data. We calculated the chemotaxis index value as: number of bacteria/motility (diameter of swimming assay). We performed the experiment as a nested factorial design.

We analysed the chemotaxis index data with a generalised linear model (GLM) with lognormal distribution in the Genmod procedure of SAS 9.3 (SAS Institute, Inc.). All blank controls had zero bacteria, so to simplify the model and eliminate this source of non-normality, we excluded them from the model. In these analyses, symbiont species (two levels: B. agricolaris and B. hayleyella), Host type (five levels: non-farmers, B. agricolaris farmers, B. hayleyella farmers, cured $B$. agricolaris farmers and cured $B$. hayleyella farmers) and their interactions were used as fixed factors. Burkholderia clone and amoeba clone were nested within symbiont species and host type, respectively. Relevant pairwise comparisons were conducted using Tukey's post-hoc tests.

Because we only had three levels of Burkholderia clones and host clones, we did not assign them as random factors in the model [48]. However, we did run a separate generalised linear mixed model (in the Glimmix procedure of 


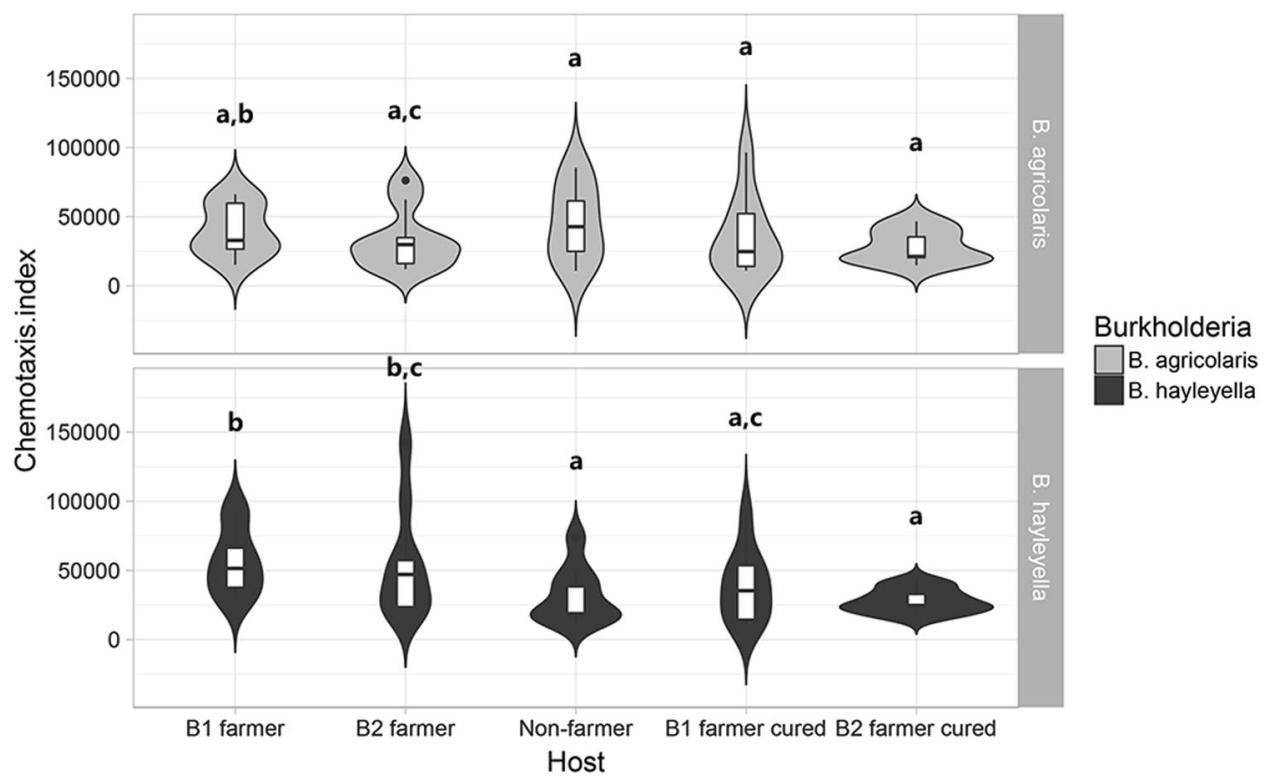

Fig. 2 Both species of farmer-associated Burkholderia isolates are attracted to amoeba secretions. The figure represents combined boxplot/violin plot diagram. Because all blank controls are zero, they are excluded from the figure (violin plot cannot be created). Results show D. discoideum supernatants invoked a strong chemotactic response by the carried Burkholderia, and that chemotaxis responses are affected

SAS 9.3 (SAS Institute, Inc.)) in which they were included as random factors (nested within symbiont species and host type), and the results were consistent with our fixed-effects model (Table S2).

A significant symbiont species main effect would indicate chemotactic divergence between the two Burkholderia species, a significant host type main effect would indicate that different host types invoke different chemotactic responses, and a significant symbiont species $\times$ host type interaction would indicate that chemotactic responses are affected by both partners.

\section{Host preferences of Burkholderia}

To test host preferences of carried Burkholderia at both species and clone levels, we used the same chemotaxis data set $(N=90)$ for this purpose. However, we analysed and plotted $B$. agricolaris and $B$. hayleyella separately. Host preference by carried Burkholderia at species level $(N=90)$ was analysed using One-way nested ANOVA, in which Burkholderia clone was nested within source of supernatant (other species, own species and own species cured). Relevant pairwise comparisons were conducted using Tukey's post-hoc tests. Host preference by Burkholderia at clone level $(N=90)$ was analysed using One-way nested ANOVA, in which Burkholderia clone was nested within source of supernatant (other host, own host and own host by both partners. Significant differences in chemotactic responses are indicated by different letters, which reflect results of a post-hoc Tukey's HSD test (Table 1). Letters apply both within and between panels (letters are the same). However, comparison between the two panels is in a pairwise pattern (vertical columns)

cured). Relevant pairwise comparisons were conducted using Tukey's post-hoc tests.

To investigate host attraction of carried vs. non-carried Burkholderia, we used the same chemotaxis data set $(N=$ 90), as well as an additional data set from non-carried Burkholderia $(N=27)$. We compared the chemotaxis index among B. agricolaris, B. hayleyella and non-carried Burkholderia using One-way nested ANOVA, in which Burkholderia clone was nested within symbiont type ( $B$. agricolaris, B. hayleyella and non-carried Burkholderia). Relevant pairwise comparisons were conducted using Tukey's post-hoc tests.

Chemotaxis index data were log-transformed to improve normality. Because all blank controls had zero bacteria, they were excluded from the analyses. Transformed data passed the normality test (Kolmogorov-Smirnov test) and tested for homogeneity of variance (Levene's test).

\section{Results}

\section{Burkholderia motility}

All Burkholderia in symbiosis with $D$. discoideum are motile but do not have social swarming motility

Chemoattraction would have little effect unless the carried Burkholderia are motile, so first of all we want to know if 
Table 1 Generalised linear models of the chemotaxis index in two Burkholderia species (B. agricolaris and B. hayleyella) in response to five D. discoideum host types in the (A) full model, (B) Post-hoc Tukey tests by host type and (C) by symbiont species. Significant effects are highlighted in bold.

\begin{tabular}{|c|c|c|c|}
\hline \multicolumn{4}{|l|}{ A) Full model } \\
\hline Fixed effects & DF & Chi-Square & $P$ \\
\hline Symbiont species & 1 & 0.74 & 0.388 \\
\hline Host type & 4 & 29.91 & $<0.001$ \\
\hline Burkholderia clone (Symbiont species) & 4 & 70.52 & $<0.001$ \\
\hline Host clone (Host type) & 10 & 143.75 & $<0.001$ \\
\hline Symbiont species*Host type & 4 & 43.45 & $<0.001$ \\
\hline \multicolumn{4}{|l|}{ B) By Host Type } \\
\hline Pairwise differences & Variance $\pm \mathrm{SE}$ & $Z$ value & $P$ \\
\hline B. agricolaris farmer (B. agricolaris vs. B. hayleyella) & $-0.302 \pm 0.181$ & -1.66 & 0.096 \\
\hline B. hayleyella farmer (B. agricolaris vs. B. hayleyella) & $-0.499 \pm 0.371$ & -1.35 & 0.178 \\
\hline Non-farmer (B. agricolaris vs. B. hayleyella) & $0.457 \pm 0.300$ & 1.52 & 0.128 \\
\hline Cured $B$. agricolaris farmer (B. agricolaris vs. B. hayleyella) & $-0.061 \pm 0.323$ & -0.19 & 0.85 \\
\hline Cured B. hayleyella farmer (B. agricolaris vs. B. hayleyella) & $0.014 \pm 0.156$ & 0.09 & 0.927 \\
\hline \multicolumn{4}{|l|}{ C) By Symbiont species } \\
\hline Pairwise differences & Variance $\pm \mathrm{SE}$ & $Z$ value & $P$ \\
\hline B. agricolaris (B. agricolaris farmer vs. non-farmer) & $-0.055 \pm 0.167$ & -0.33 & 0.997 \\
\hline B. agricolaris (B. agricolaris farmer vs. B. hayleyella farmer) & $0.167 \pm 0.170$ & 0.98 & 0.863 \\
\hline B. agricolaris (B. agricolaris farmer vs. cured B. agricolaris farmer) & $0.266 \pm 0.215$ & 1.24 & 0.73 \\
\hline B. agricolaris (B. agricolaris farmer vs. cured B. hayleyella farmer) & $0.320 \pm 0.185$ & 1.73 & 0.418 \\
\hline B. agricolaris (B. hayleyella farmer vs. non-farmer) & $-0.222 \pm 0.178$ & -1.25 & 0.722 \\
\hline B. agricolaris (B. hayleyella farmer vs. cured $B$. hayleyella farmer) & $0.153 \pm 0.195$ & 0.79 & 0.935 \\
\hline B. agricolaris (cured B. agricolaris farmer vs. cured B. hayleyella farmer) & $0.054 \pm 0.235$ & 0.23 & 0.999 \\
\hline B. agricolaris (cured B. agricolaris farmer vs. non-farmer) & $-0.321 \pm 0.221$ & -1.45 & 0.595 \\
\hline B. agricolaris (cured B. agricolaris farmer vs. B. hayleyella farmer) & $-0.099 \pm 0.223$ & -0.44 & 0.992 \\
\hline B. agricolaris (cured B. hayleyella farmer vs. non-farmer) & $-0.375 \pm 0.193$ & -1.95 & 0.292 \\
\hline B. hayleyella (B. agricolaris farmer vs. non-farmer) & $0.565 \pm 0.210$ & 2.69 & 0.007 \\
\hline B. hayleyella (B. agricolaris farmer vs. B. hayleyella farmer) & $0.149 \pm 0.182$ & 0.82 & 0.411 \\
\hline B. hayleyella (B. agricolaris farmer vs. cured B. agricolaris farmer) & $0.543 \pm 0.268$ & 2.02 & 0.043 \\
\hline B. hayleyella (B. agricolaris farmer vs. cured B. hayleyella farmer) & $0.693 \pm 0.230$ & 3.01 & 0.003 \\
\hline B. hayleyella (B. hayleyella farmer vs. non-farmer) & $0.416 \pm 0.236$ & 1.77 & 0.057 \\
\hline B. hayleyella (B. hayleyella farmer vs. cured B. hayleyella farmer) & $0.544 \pm 0.254$ & 2.15 & $\mathbf{0 . 0 3 2}$ \\
\hline B. hayleyella (cured B. agricolaris farmer vs. cured B. hayleyella farmer) & $0.150 \pm 0.322$ & 0.47 & 0.64 \\
\hline B. hayleyella (cured B. agricolaris farmer vs. non-farmer) & $0.023 \pm 0.308$ & 0.07 & 0.95 \\
\hline B. hayleyella (cured B. agricolaris farmer vs. B. hayleyella farmer) & $-0.393 \pm 0.289$ & -1.36 & 0.173 \\
\hline B. hayleyella (cured B. hayleyella farmer vs. non-farmer) & $-0.128 \pm 0.275$ & -0.46 & 0.643 \\
\hline
\end{tabular}

they can move. We tested this by using standard plate-based bacterial swimming and swarming assays [39, 40], with non-motile Klebsiella pneumoniae as a negative control and three motile Burkholderia (B. unamae [41], B. tuberum [43] and $B$. silvatlantica [42]) as positive controls. We found that all six carried Burkholderia clones are motile, though they differ in motility (movement diameters across the plate ranging from 2.078 to $2.951 \mathrm{~cm}$ while non-motile $K$. pneumoniae is $0.853 \mathrm{~cm}$, Figure $\mathrm{S} 1$ ). However, there are no significant differences among B. agricolaris (B1qs70, B1qs159 and B1nc21), B. hayleyella (B2qs11, B2qs21 and B2nc28), and the three non-carried Burkholderia species ( $N$ $=9, F_{2,6}=0.313, P=0.743$ ), indicating that this is likely to be an ancestral trait not particularly evolved for symbiosis. In the swarm assay, all nine tested clones lack swarming ability (Figure S2). So Burkholderia swim but do not do so socially. 
Fig. 3 Carried Burkholderia are more attracted to $D$. discoideum secretions than are non-carried Burkholderia, but they do not prefer hosts of their own clones or species. To investigate how specific these chemotactic responses are and whether carried Burkholderia would prefer their original hosts, we studied host preferences at three different levels. The figure shows mean \pm SEs of chemotactic responses. a Carried Burkholderia were more attracted to $D$. discoideum secretions (from all clones) than non-carried Burkholderia. b $B$. hayleyella and B. agricolaris did not prefer hosts of their own species. c Each Burkholderia clone did not prefer its own host clone. Significant differences in chemotactic responses are indicated by different letters, which represent results of oneway nested ANOVA test and followed by a post-hoc Tukey's honestly significantly different (HSD) test. Letters apply within panel (a), (b) and (c). For panels (b) and (c), letters apply within B. hayleyella and B. agricolaris

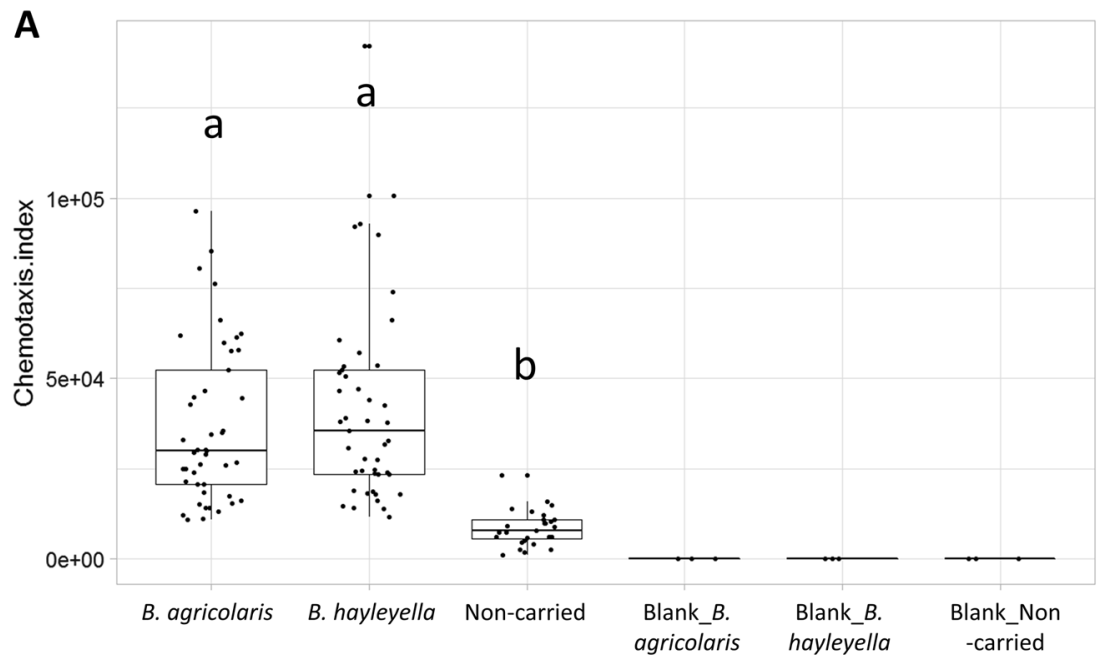

B

B. agricolaris

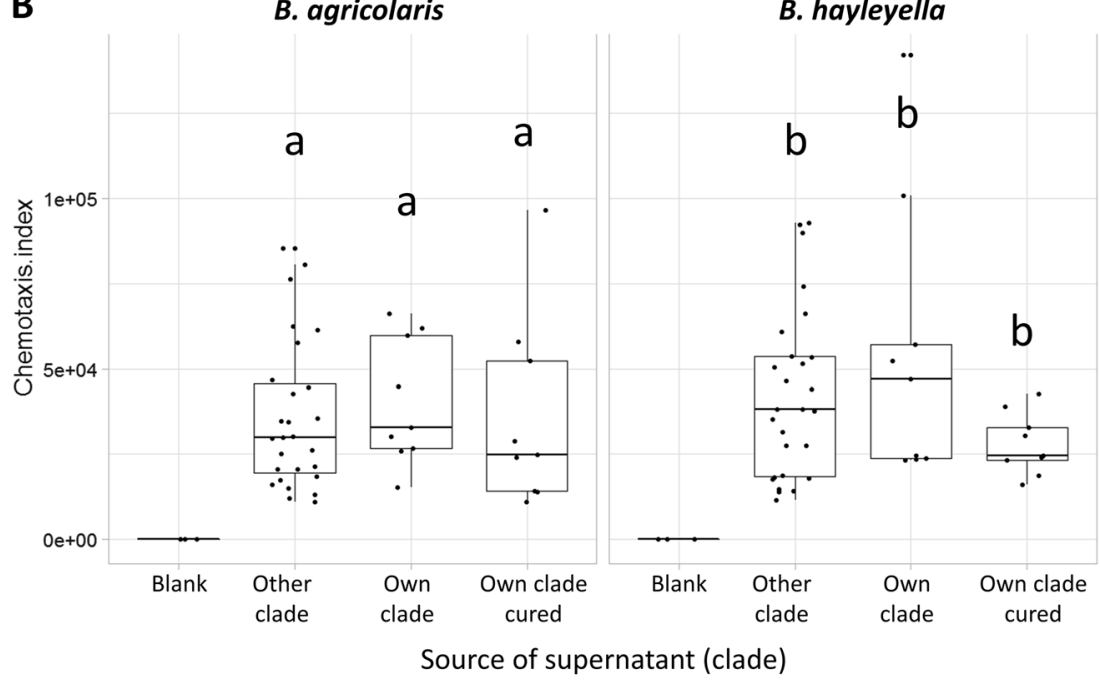

C

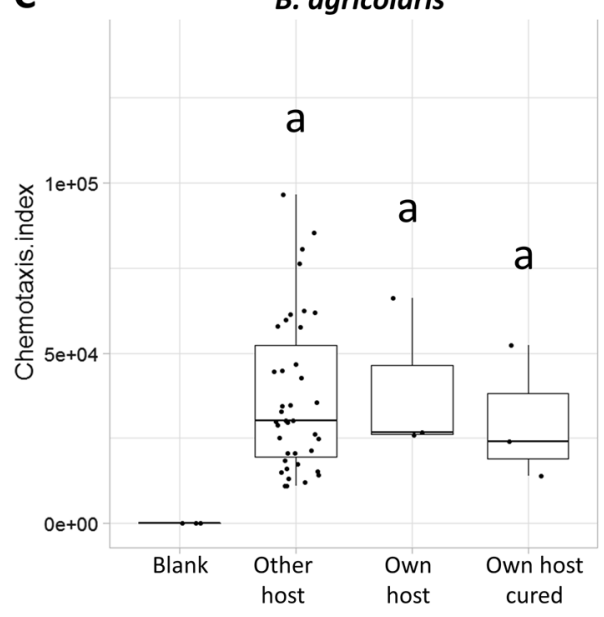

B. hayleyella

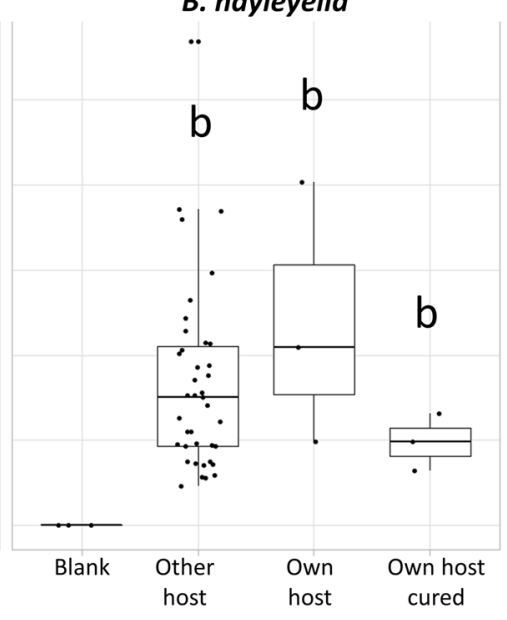

Source of supernatant (clone) 


\section{Partner attraction and choice}

\section{Carried Burkholderia chemotax towards amoeba supernatant and $B$. hayleyella prefers farmer supernatant}

To test whether carried Burkholderia are attracted to their amoeba hosts, we used amoeba supernatant as a stand-in for the actual amoebas to rule out any amoeba action. We used the supernatants as chemoattractants in a capillary chemotaxis assay. We tested three clones each of $B$. agricolaris and $B$. hayleyella with supernatants from five host types: $B$. agricolaris farmers, $B$. hayleyella farmers, non-farmers, cured $B$. agricolaris farmers and cured $B$. hayleyella farmers, using three different amoeba clones from each. Amoeba supernatants invoked a strong chemotactic response by the carried Burkholderia (Fig. 2), as shown by the accumulation of bacteria in supernatant-containing syringes while no bacteria were found in the control syringes (containing KK2 buffer). To further investigate what kind of partner attraction exists, we analysed the data set using a generalised linear model.

We found a significant symbiont species $\times$ host type interaction (Table 1A), indicating two Burkholderia species behave differently in response to the five different host types (Fig. 2). To establish the nature of these interactions, we next investigated the potential effects of the symbionts and hosts in chemotactic responses by host type (Table 1B) and by symbiont species (Table 1C), respectively.

When analysed by host type, pairwise comparisons suggest that there was no difference between $B$. agricolaris and $B$. hayleyella in response to all host types (Table $1 \mathrm{~B}$, Fig. 2). These results suggest that both $B$. agricolaris and $B$. hayleyella are equally attracted to amoeba supernatants.

When analysed by symbiont species, multiple comparisons suggest that different host types invoke different chemotactic responses (Table 1C, Fig. 2). All host types induced equal responses to B. agricolaris (Table 1C, Fig. 2). However, B. agricolaris farmers and B. hayleyella farmers are generally more attractive to $B$. hayleyella compared to non-farmers (Table 1C, Fig. 2).

\section{Removal of Burkholderia from farmer clones decreases chemotactic responses in $B$. hayleyella}

To investigate if the presence of Burkholderia would make any differences to the chemotactic responses, we removed the Burkholderia from both B. agricolaris and B. hayleyella farmers. When Burkholderia were removed from their farmer hosts, these cured farmers induced similar chemotactic responses as non-farmers (Fig. 2, Table 1C). B. agricolaris and $B$. hayleyella were equally attracted to nonfarmers and cured farmers (Fig. 2, Table 1C). In addition, two species respond differently to curing of hosts (Fig. 2,
Table 1C). Removal of B. agricolaris seemed to have no effect to their chemotactic responses (Fig. 2, Table 1C). However, removal of $B$. hayleyella decreases the chemotactic responses compared to uncured farmers (Fig. 2, Table 1C, both B. agricolaris and B. hayleyella farmers).

Taken together, these results suggest that all carried Burkholderia are attracted to $D$. discoideum clones from which they were isolated. However, B. hayleyella exhibits specific choice towards the uncured farmer $D$. discoideum clones while B. agricolaris does not.

\section{Host preferences of Burkholderia}

Next, we want to know how specific these chemotactic responses are and whether farmer-associated Burkholderia would prefer their original farmer hosts. We investigated host preferences at three different levels and ask three corresponding questions: (1) Are carried Burkholderia more attracted to host secretions than non-carried Burkholderia? (2) Are B. agricolaris and B. hayleyella Burkholderia more attracted to their own hosts of their species and (3) Is each Burkholderia clone more attracted to its own host?

\section{Host attraction of carried Burkholderia vs. non-carried bacteria}

We find strong evidence that chemotactic responses to $D$. discoideum hosts are relatively specific to carried Burkholderia. There are significant differences in attraction to $D$. discoideum among B. agricolaris, B. hayleyella and the three non-carried Burkholderia tested (One-way nested ANOVA, $\left.F_{2,6}=29.393, P=0.001\right)$. Both $B$. agricolaris (pairwise Tukey tests, $P<0.001$ ) and $B$. hayleyella (pairwise Tukey tests, $P<0.001)$ are more attracted to host secretions than are non-carried Burkholderia (Fig. 3a). All blank controls invoked zero response (no bacteria in both blank controls, Fig. 3a). B. tuberum, which is within the same major clade as the carried Burkholderia [31, 49], does not show higher attraction to $D$. discoideum compared to non-carried B. unamae (Tukey post-hoc test, $P=0.198$, Figure S3) and B. silvatlantica (Tukey post-hoc test, $P=$ 0.677 , Figure S3).

To further investigate how other bacteria respond to amoeba secretions, we performed additional experiments on nine strains of seven different bacterial species (Pseudomonas aeruginosa, Serratia marcescens, Bacillus subtilus, Staphylococcus aureus, Burkholderia fungorum, Burkholderia xenovorans, Escherichia coli (536), E. coli (ColF6c) and E. coli (IA152)). For logistical reasons, we only tested them on one amoeba supernatant (QS9). We found that all tested bacterial species showed some degree of attraction to amoebal secretion (Figure S4), and they differed in their chemotactic responses (one-way ANOVA, 
Fig. 4 Only clone B. agricolaris B1qs70 shows much Burkholderia-Burkholderia. The figure represents a heat map of the chemotactic responses using Burkholderia supernatant or a blank control. The chemotactic responses of the carried Burkholderia are indicated by varying colour intensities according to the legend at the top of the figure. The $y$-axis represents Burkholderia supernatants and the $x$-axis represents each Burkholderia clone. The colour key represents the value of the chemotaxis index
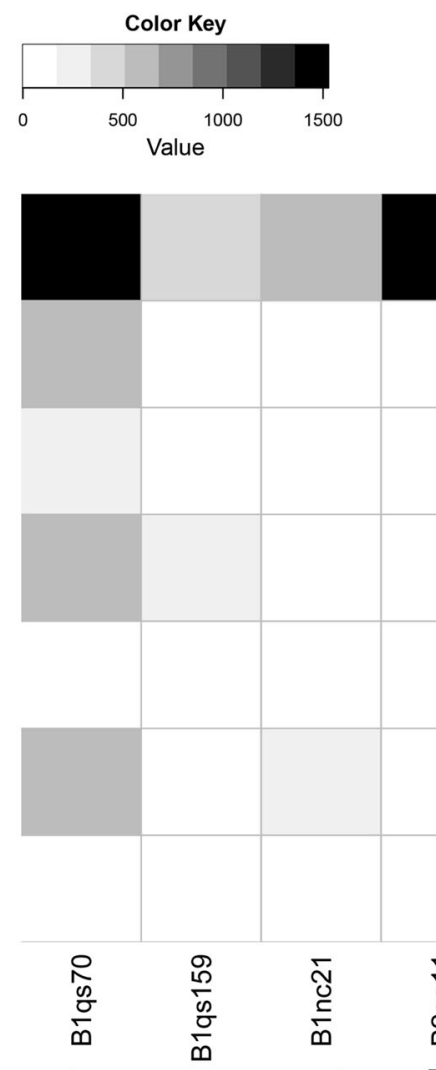

B. agricolaris

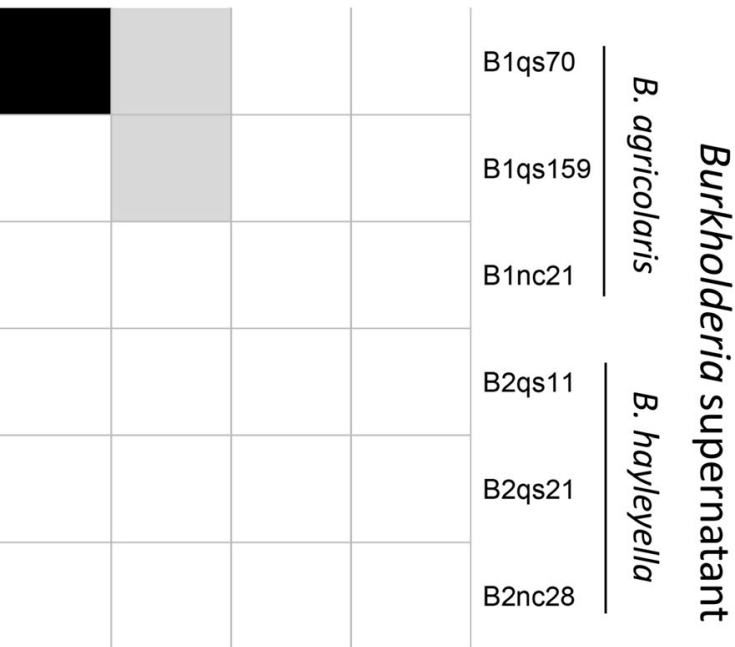

\section{Burkholderia clone}

$P<0.001$, Figure S4). However, these attractions are significantly weaker compared to those of carried symbionts (Figure S5). Carried symbionts showed significantly higher attraction than non-carried Burkholderia (pairwise Tukey tests, $P=0.018$, Figure S5) and other bacterial species (pairwise Tukey tests, $P<0.001$, Figure S5) to amoeba secretion, while there is no difference between non-carried Burkholderia and other bacterial species (pairwise Tukey tests, $P=0.277$ Figure S5).

\section{Preference for hosts of the same Burkholderia species}

We find no evidence that $B$. agricolaris and B. hayleyella are more attracted to hosts of their own species (Fig. 3b). For $B$. agricolaris, the one-way ANOVA of chemotaxis index on the measure of host preference revealed no statistically significant main effect (One-way nested ANOVA, $F_{2,6}=0.690, P=0.523$ ), indicating that no host preference was found in $B$. agricolaris for $B$. agricolaris hosts (Fig. 3b). For $B$. hayleyella, no statistically significant main effect was found either (One-way nested ANOVA, $F_{2,6}=$ $1.197, P=0.354)$.

\section{Host preference of specific clone}

At the clone level, the statistical patterns here are exactly the same as in the previous section: there is no evidence that shows Burkholderia clones are more attracted to their own host (Fig. 3c). Again, B. agricolaris show no host specificity (one-way nested ANOVA, $F_{2,6}=0.182, P=0.835$, Fig. 3c). B. hayleyella also have no statistically significant main effect (One-way nested ANOVA, $F_{2,6}=0.897, P=$ 0.430).

\section{Contribution of Burkholderia-Burkholderia attractions to overall chemotactic responses}

As farmer clones are carrying Burkholderia throughout our experimental procedure (except in the cured treatments), it is possible that these carried Burkholderia may also secrete attractive compounds into the amoeba supernatants being tested. Therefore, our overall chemotactic responses could be affected by the Burkholderia-Burkholderia attractions. To test this, we performed an additional experiment to test the attractiveness of Burkholderia secretions. We prepared Burkholderia supernatants from equal (or slightly higher) number of Burkholderia $\left(10^{9}\right.$ cells $)$ as in the amoeba 
A

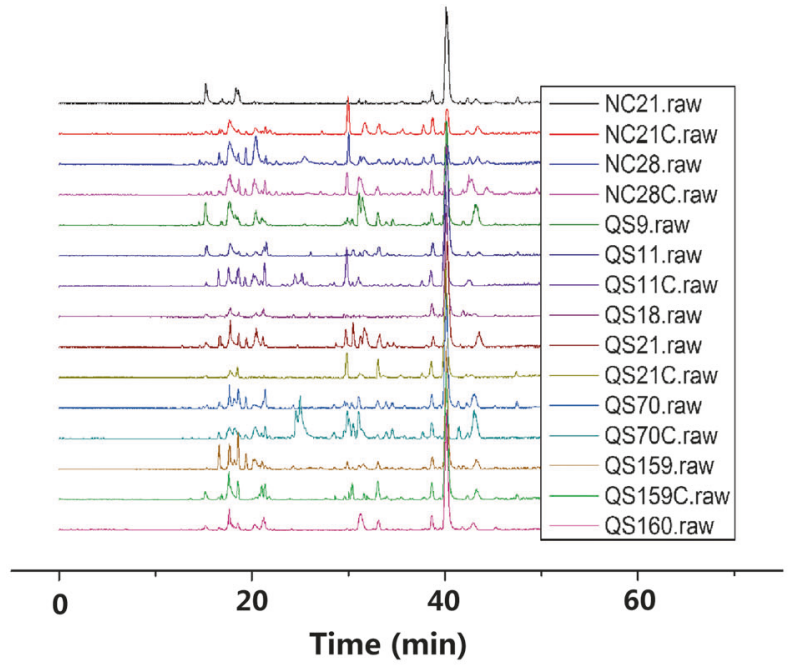

C

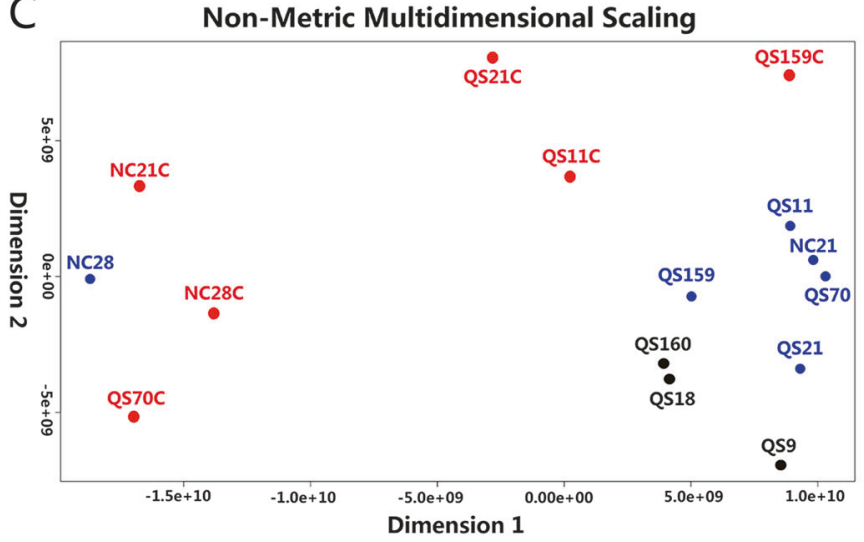

B

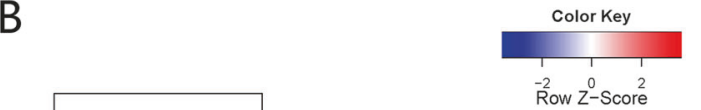

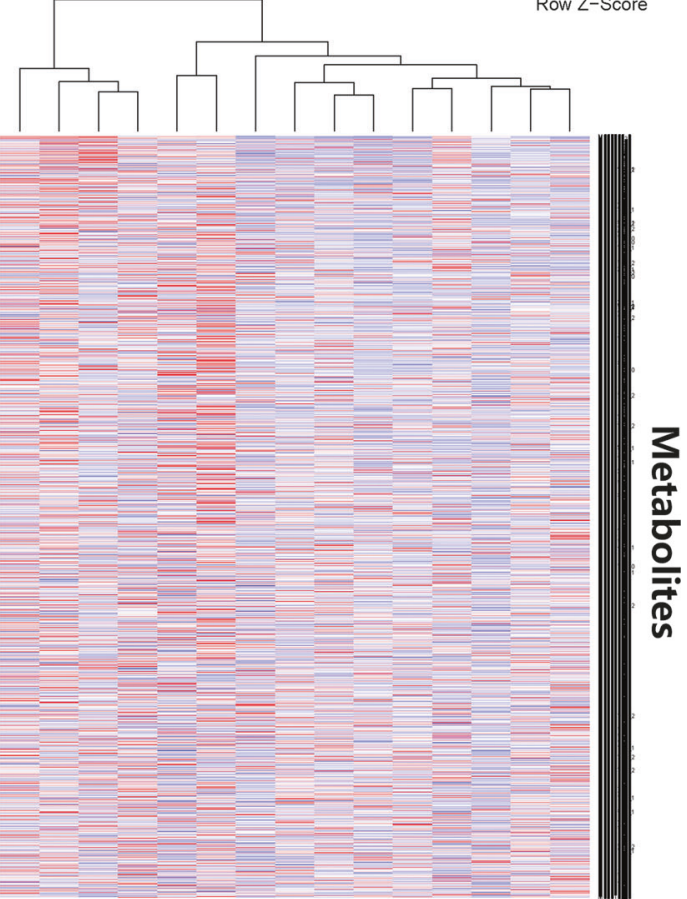

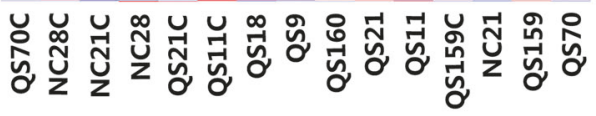

Dictyostelium clones
Fig. 5 Metabolomics analysis of extracellular metabolites in supernatant of $D$. discoideum. Tested clones are identified by QS or NC numbers, with a trailing ' $\mathrm{C}$ ' indicating that the clone was cured of its symbiont. a HPLC-MS analysis of $D$. discoideum extracellular metabolites. Base peak ion (BPI) chromatograms obtained from the $15 \mathrm{D}$. discoideum clones are shown. The $y$-axis represents relative abundance and the $x$-axis represents retention time. b Heat map of all identified extracellular metabolites from $15 \mathrm{D}$. discoideum clones. The

supernatant experiment (vs. $10^{8}$ amoeba cells, and each amoeba has 2-10 Burkholderia bacteria inside, L. Shu, personal observations).

Overall, Burkholderia supernatants invoked a very minor chemotactic response (chemotaxis index: $235.51 \pm 43.98$, mean \pm S.E.), which is less than $1 \%$ compared to that of amoeba supernatants (chemotaxis index: 40247.31 \pm 1709.207, mean \pm S.E.) by the carried Burkholderia (Fig. 2 and Fig. 4). A Mann-Whitney $U$ test indicated that amoeba supernatants were statistically significantly more attractive to carried Burkholderia than the Burkholderia supernatants $\left(N_{\text {amoeba }}=6, N_{\text {Burkholderia }}=6, U=0.000, P=0.002\right)$. Taken together, these data suggest that the global chemotactic responses are unlikely to be strongly affected by the Burkholderia-Burkholderia attractions. abundance of each metabolite is indicated by varying colour intensities according to the legend at the top of the figure. The colour key represents the $z$-score, the deviation from the mean by standard deviation units. c Non-metric multidimensional scaling analysis to show the similarity of extracellular metabolites from $15 \mathrm{D}$. discoideum clones. Colours indicate different $D$. discoideum. Blue, farmer clones. Black, non-farmer clones. Red, cured farmer clones

Within the Burkholderia-Burkholderia attraction experiment, most Burkholderia supernatants actually invoked zero chemotactic response (Fig. 4). Interestingly, most of the chemotaxis response happened in one specific B. agricolaris clone, B1qs70 (Fig. 4). Clone B1qs70 both attracted most other clones and was attracted to most other clones. However, it is not clear why this clone shows a different pattern.

\section{Composition of the attractive supernatant}

\section{Global analysis of extracellular metabolites}

To begin to identify potential chemoattractants and to look for chemical differences that might explain the patterns shown above, we explored the extracellular metabolites of 


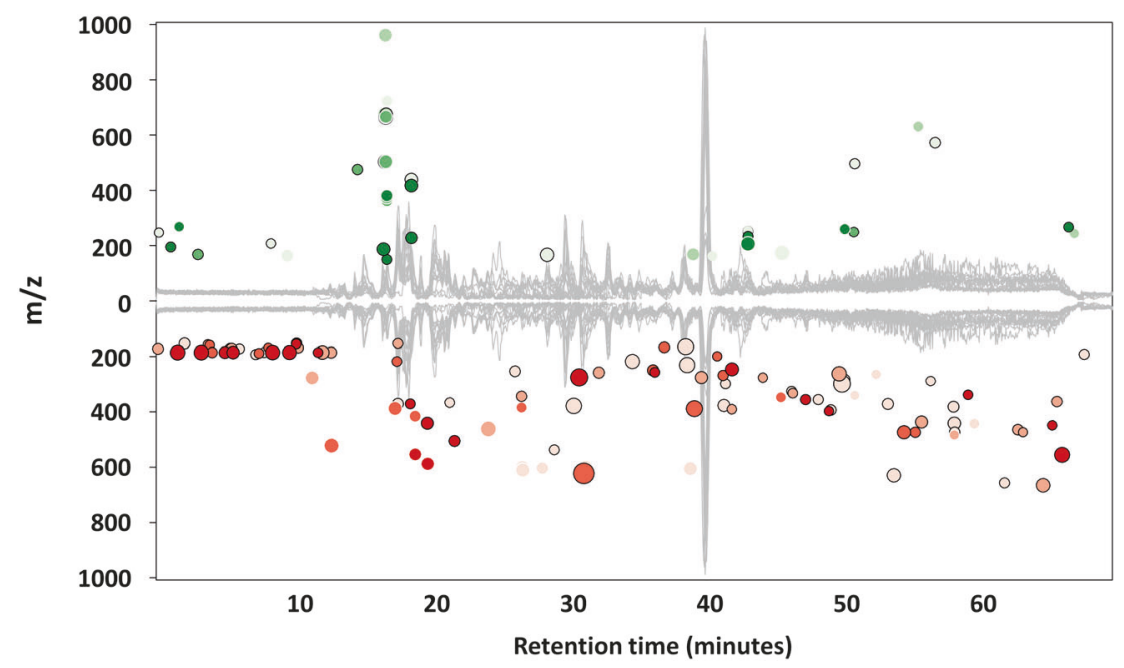

Fig. 6 Group comparison to identify farmer specific molecules. Cloud plot of differences between farmers and non-farmers plus cured farmer of 155 features with $p$-value $\leq 0.01$ and fold change $\geq 2$. The y coordinate of each feature corresponds to the mass-to-charge ratio of the compound as determined by mass spectrometry. Features whose intensity is increased in farmers are shown on the top plot in green,

each $D$. discoideum clone using an untargeted metabolomics approach. We found both qualitative and quantitative variations in base peak intensity of chromatograms across different $D$. discoideum clones (Fig. 5a).

To investigate the global pattern of $D$. discoideum supernatants, we further identified the metabolites using HPLC-MS/MS and analysed the data set using XCMS Online [45, 47]. XCMS is a widely used, cloud-based platform designed to process untargeted metabolomics data [46, 47, 50]. Overall, a large number of features was identified in each clone, ranging from 16214 to 22431 (Fig. 5b). To visualise the level of similarity of individual $D$. discoideum clones, we analysed the data set using a nonmetric multidimensional scaling (Fig. 5c). Farmers (blue dots) and non-farmers (black dots) are generally clustered together. However, cured farmers (red dots) are scattered and distinct, with one exception, from both farmers and non-farmers (Fig. 5c). Interestingly, based on the chemotaxis experiment, non-farmers and cured farmers are equally attractive to both species of Burkholderia, even though they actually differ widely in their metabolomics compositions. In addition, we found considerable variation within cured farmers. These results suggest that cured farmers are not as similar to non-farmers as we expected, and the presence of Burkholderia makes a big difference to the metabolomics profiles of $D$. discoideum hosts.

\section{Identification of potential chemoattractants}

Compounds of interest can sometimes be identified from the differences between two groups [45]. The strongest group whereas features whose intensity is decreased in farmers are shown on the bottom plot in red. The diameter of each bubble corresponds to the log fold change of the feature: the larger the bubble, the larger the fold change. The intensity of the feature's colour represents the statistical significance of the fold change, where features with low p-values are brighter compared to features with high $p$-values

difference from our capillary assays was between supernatants from $D$. discoideum (farmers) carrying Burkholderia vs. D. discoideum not carrying Burkholderia (non-farmers and cured farmers). This approach might identify compounds that were specific to farmers or it might identify compounds that were generally important in attracting Burkholderia, but present more in farmers.

We therefore performed a group comparison of metabolites between farmers and non-farmers/cured farmers. We identified 155 features that were altered with fold changes greater than 2 and $p$-values less than 0.01 (Fig. 6a). Of these, 52 features have higher abundances in farmer groups (Fig. 5), so these are candidate chemoattractants to $B$. hayleyella.

One potential caveat of the XCMS approach is its false positive features. To investigate this we validated these 52 features by manually checking the extracted ion chromatogram at XCMS Online and removing the ones with low signal to noise ratio. Furthermore, we found that the isotopic peaks of the same compound could be identified as individual features. Therefore, we checked the isotopic pattern of each feature on their mass spectra in raw data and reassigned the monoisotopic peak as the $\mathrm{m} / \mathrm{z}$ value. We finally identified 18 features that are candidates of attractants to B. hayleyella (Table 2).

Among those 18 features, 12 were isolated by the mass spectrometer to generate fragment ion spectra. MS/MS data of the other six features were not obtained due to their low abundance and the limited capability of the mass spectrometer. We tried to identify those 12 features by carefully examining their fragment ion spectra. First, we compared 
Table 2 List of chemoattractant candidates for B. hayleyella. All of the peptides yielded hits in the D. discoideum database (but not in the Burkholderia database)

\begin{tabular}{|c|c|c|c|c|c|}
\hline ID & Fold change & Retention time (min) & Precursor $\mathrm{m} / \mathrm{z}$ & Putative compound or peptide sequence & Notes \\
\hline 1 & 2.6 & 14.7 & $474.9315, z=3$ & *PKE*PVVEEPP* & RNA recognition motif-containing protein \\
\hline 2 & 3.9 & 16.8 & $657.6403, z=3$ & *PPP*PPEPPE* & Actin-binding protein \\
\hline 3 & 4.8 & 16.8 & $663.3154, z=3$ & $*$ PPP*PPEPPE* $+\mathrm{NH}_{3}$ & Actin-binding protein \\
\hline 4 & 5.3 & 16.8 & $670.2897, z=3$ & *PРPP* & $\mathrm{AAA}+\mathrm{ATPase}$ \\
\hline 5 & 3.8 & 16.8 & $664.9665, z=3$ & *PV*VPA* & DOCK family protein \\
\hline 6 & 3.6 & 16.8 & $675.2771, z=3$ & $* \mathrm{PPPP}^{*}+14.96 \mathrm{Da}$ & AAA + ATPase \\
\hline 7 & 3.8 & 16.9 & $373.6064, z=?$ & 2 candidates & No MS/MS \\
\hline 8 & 2.7 & 16.9 & $722.2476, z=1$ & 6 candidates & Unknown \\
\hline 9 & 3.4 & 16.9 & $380.6007, z=2$ & 2 candidates & Unknown \\
\hline 10 & 4 & 18.7 & $439.0991, z=1$ & 3 candidates & Unknown \\
\hline 11 & 3.2 & 18.7 & $228.0354, z=?$ & 10 candidates & No MS/MS \\
\hline 12 & 4 & 18.7 & $417.1170, z=1$ & 58 candidates & Unknown \\
\hline 13 & 3.6 & 39.3 & $168.5831, z=?$ & 57 candidates & Tripeptide, but no MS/MS \\
\hline 14 & 5.7 & 43.3 & $206.5984, z=?$ & 9 candidates & Tripeptide, but no MS/MS \\
\hline 15 & 2.2 & 43.3 & $251.1633, z=1$ & 3,5-Di-tert-butyl-4-hydroxybenzoic acid & BHT metabolite \\
\hline 16 & 2.3 & 43.3 & $233.1534, z=1$ & 158 candidates & No MS/MS \\
\hline 17 & 6.2 & 45.8 & $173.5934, z=?$ & 35 candidates & Tripeptide, but no MS/MS \\
\hline 18 & 2.4 & 51.1 & $496.3019, z=1$ & 3 candidates & Lipid molecule \\
\hline
\end{tabular}

*one or more amino acid residue. The sequence may also be reversed

the $\mathrm{m} / \mathrm{z}$ difference between major peaks against residue mass of the 20 amino acids to distinguish peptides from other metabolites. Incomplete peptide sequences are proposed by following series of $\mathrm{b}$ and $\mathrm{y}$ ions on the spectra. Because we can't distinguish between $b$ and $y$ ions, the reverse of the sequences shown in Table 2 may also be possible. Interestingly, all six peptides we found are prolinerich peptides. Two sets of peptides, $\mathrm{m} / \mathrm{z}=657.6403$ and 663.3154, $\mathrm{m} / \mathrm{z}=670.2897$ and 675.2771, have almost identical fragment ions. They could be peptides with the same sequence but different modifications or adducts. All peptide sequences were blasted against non-redundant protein sequences for $D$. discoideum and Burkholderia using BLASTP [51]. All peptides yielded perfect hits in the D. discoideum database, but none of them did in Burkholderia, indicating these peptides are from amoebas rather than Burkholderia. Top hits are selected and shown in Table 2.

After identification of peptides, we submitted the MS/MS results of the remaining 6 metabolites to MassBank [52], mzCloud (mzcloud.org), HMDB [53] and METLIN [54] for spectra matching. However, we were unable to match fragment ion spectra of most of the metabolites. They could be new metabolites or ones in the database without MS/MS information. Their exact mass and assigning MS/MS peaks are listed in Table 2. We identified one feature $(\mathrm{m} / \mathrm{z}=$ 251.1633) as 3,5-di-tert-butyl-4-hydroxybenzoic acid with high confidence. 3,5-di-tert-butyl-4-hydroxybenzoic acid
$\left(\mathrm{C}_{15} \mathrm{H}_{22} \mathrm{O}_{3}\right)$ is a carboxylic acid. We are not able to find any related literatures on its biological function. However, some evidence links it to another chemical butylated hydroxytoluene (BHT), which is an artificial antioxidant agent.

For the features that are not identified by MS/MS, we found 2-158 candidates for each feature by searching their accurate mass in the METLIN database (Supplementary Information 2). All candidates have a mass difference less than $5 \mathrm{ppm}$, which is limited by the resolution of the mass spectrometer. Due to structure variation and limitation of the database, we are unable to determine the exact structures of those features. However, the compound has an $\mathrm{m} / \mathrm{z}=$ 168.5831 is likely to be a tripeptide and the compound of 496.3019 can be a lipid molecule.

\section{Discussion}

This study has identified mechanisms for forming and maintaining Dictyostelium-Burkholderia symbioses. We show that partner-finding plays a significant role in this mutualistic associations of microbial systems. Out study suggests that active partner-finding by bacteria is an important feature not just in mutualisms with animals and plants, but also with protists. Our study also highlights that chemotaxis is an important modality of partner-finding, just like visual, olfactory and auditory cues are in other cooperative interactions, such as mating choice or pollination. 
We can now reject the hypothesis that initiation of associations is no more complex than the haphazard ingestion of Burkholderia by amoebas. We can also reject the hypothesis that the attraction to Dictyostelium is a trait of Burkholderia in general. The genus Burkholderia belongs to the class $\beta$-Proteobacteria and is widely distributed in the environment. They are abundant in soil and they can be associated with a wide range of plants [55], invertebrates [56, 57] and fungi [21]. The two species of carried Burkholderia are more attracted to amoeba secretions than are the non-carried Burkholderia species we tested. This shows that the association of these two Burkholderia species with $D$. discoideum is not a random or accidental infection process. Instead, the association is sought out specifically by those Burkholderia that live inside $D$. discodeum, strongly suggesting that this chemotaxis is a partner-finding adaptation. Other non-carried bacterial species did show a very small amount of attraction to Dictyostelium supernatants, suggesting that the partnerfinding adaptation is likely evolved from a more generalised response.

However, we did not find much evidence for carried Burkholderia making specialised choices among hosts. One exception is that the $B$. hayleyella, but not the $B$. agricolaris, prefers farmer clones over non-farmer and cured farmer clones. Why they would be attracted specifically to infected hosts is uncertain, but this evidence might suggest that $B$. hayleyella is more co-evolved with amoeba farmers perhaps because of a longer history of co-evolution with $D$. discoideum than $B$. agricolaris in nature. To validate this hypothesis, further comparative studies between these two species are needed. However, co-evolution with respect to attraction does not appear to be very specific. Burkholderia clones are not specifically attracted to their own particular host clone, nor to other hosts of their own species. This suggests that host clone switching or horizontal transmission may occur often enough to prevent the more specific co-evolution that can occur under strict vertical transmission. Though these bacteria are endosymbionts that live inside the host [31], they are apparently not obligate endosymbionts. They can still grow independently of their hosts in the lab, and their retention of motility suggests that they also do so in nature.

This kind of chemotaxis mediated partner-finding mechanism has only been reported in the interactions between bacteria and their multicellular eukaryotic hosts [14, 15, 18-21]. For instance, in the rhizobia-legume system free-living rhizobia are attracted to the environment around legume root hairs through chemotaxis $[8,17,58]$. In another model symbiosis, the squid-vibrio system, the marine bacterium $V$. fischeri uses chemotaxis to move towards and colonize the squid (E. scolopes) light organs [14]. Our study shows that bacteria can use the same partner-finding mechanism to interact with unicellular eukaryotic hosts and suggests that bacterial chemotaxis is a general feature of eukaryotic host-bacterial symbioses.

We used metabolomics to try to identify candidate chemoattractant compounds, exploiting differences between farmers vs. non-farmers and cured farmers. For our short list of candidates that passed quality controls, six did not yield useful MS/MS data. Among the remaining twelve were six proline-rich peptides. The rest failed to generate hits in the databases, with the exception of 3,5-di-tert-butyl-4-hydroxybenzoic acid. Previous studies suggest that 3,5-di-tertbutyl-4-hydroxybenzoic acid is involved in the metabolic pathway of (BHT) in rat and human [59, 60]. In addition, some phytoplankton, including the green algae Botryococcus braunii and three different cyanobacteria (Cylindrospermopsis raciborskii, Microcystis aeruginosa and Oscillatoria sp.) are capable of producing BHT, which may link to the reactive oxygen species production in these species [61, 62]. However, this compound seems unlikely to be of biological origin and could simply be a breakdown product of the preservative BHT (Jon Clardy, pres. comm.). Among the rest of unknown features, additional identification by searching their accurate mass in the METLIN database suggests that the compound has an $\mathrm{m} / \mathrm{z}=168.5831$ is likely to be a tripeptide and the compound of 496.3019 can be a lipid molecule (Supplementary Information 2). These results indicate that attraction of the symbionts is likely related to various metabolism processes. However, finding the exact chemoattractants is going to require additional work. Metabolites from amoebae are produced in extremely low quantities, which makes it virtually impossible to do a full structure elucidation via NMR [63]. Due to these difficulties, it is likely that natural products from the social amoebae have to be discovered through heterologous expression of the respective gene clusters [63].

Our study also has some implications for human disease and health. Amoebas have served as model systems for studying ecology, evolution and biology of pathogenic bacteria [64-66]. D. discoideum cells are professional phagocytes, and the core function of the innate immune response is evolutionarily conserved between amoebas and human professional phagocytic cells [36]. Our study shows that bacteria can actively move towards phagocytic cells. This is quite interesting because generally bacteria are thought to evade phagocytic killing rather than running into it [67]. However, given that amoebas have interacted with bacteria for a long time, even before animals appeared [68, 69], it is not surprising that some bacteria have evolved mechanisms that specifically target and exploit phagocytic cells and this could affect how these bacteria interact with our immune systems.

Future research should address the reverse question, whether Dictyostelium is particularly attracted to $B$. 
hayleyella and B. agricolaris. The fitness consequences to the host are context dependent and sometimes negative; it is costly to carry Burkholderia in circumstances (high food) where the farming trait is unnecessary [23]. If the amoebas are attracted by these Burkholderia it would suggest that the relationship is a net beneficial one; if they are repelled, it would suggest the opposite. Future research should also address the genetic basis of these interactions, given that several chemotaxis related genes have been identified in related species [70-72].

Acknowledgements Many thanks to Jon Clardy, Pierre Stallforth, Roman Stocker and to our laboratory group for useful discussions, and to Mountain Lake Biological Station of the University of Virginia where we collected the samples. L.S., J.E.S. and D.C.Q. conceived and planned the study. L.S. performed the experiments and conducted the statistical analyses. B.Z. participated in the metabolomics experiments. All authors contributed to the writing of the manuscript and read and approved the final manuscript.

Funding: This material is based upon work supported by the Life Sciences Research Foundation and Simons Foundation (to L.S.), the National Science Foundation under grant nos. NSF IOS 1656756, NSF DEB1146375, NSF IOS 1256416, and the John Templeton Foundation grant no. 43667. Mass spectrometry is supported by the National Institutes of Health $(\mathrm{NIH})$, the National Institute of General Medical Sciences (NIGMS) 2P41GM103422.

\section{Compliance with ethical standards}

Conflict of interest The authors declare that they have no conflict of interest.

\section{References}

1. Noë R. In: Jaramvh RN, Hammerstein P. (eds.) Biological markets: partner choice as the driving force behind the evolution of cooperation. Economics in Nature. Social Dilemmas, Mate Choice and Biological Markets. Cambridge: Cambridge University Press. 2001; pp 93-118.

2. Schaefer HM, Schaefer V, Levey DJ. How plant-animal interactions signal new insights in communication. Trends Ecol Evol. 2004;19:577-84.

3. Candolin U. The use of multiple cues in mate choice. Biol Rev. 2003;78:575-95.

4. Andersson M, Simmons LW. Sexual selection and mate choice. Trends Ecol Evol. 2006;21:296-302.

5. Miller MB, Bassler BL. Quorum sensing in bacteria. Annu Rev Microbiol. 2001;55:165-99.

6. Strassmann JE, Gilbert OM, Queller DC. Kin discrimination and cooperation in microbes. Annu Rev Microbiol. 2011;65:349-67.

7. Velicer GJ, Vos M. Sociobiology of the Myxobacteria. Annu Rev Microbiol. 2009;63:599-23.

8. Wadhams GH, Armitage JP. Making sense of it all: bacterial chemotaxis. Nat Rev Mol Cell Biol. 2004;5:1024-37.

9. Bagorda A, Parent CA. Eukaryotic chemotaxis at a glance. J Cell Sci. 2008;121:2621-4

10. Dormann D, Weijer CJ. Chemotactic cell movement during development. Curr Opin Genet Dev. 2003;13:358-64.

11. Dormann D, Weijer CJ. Chemotactic cell movement during Dictyostelium development and gastrulation. Curr Opin Genet Dev. 2006;16:367-73.
12. Roussos ET, Condeelis JS, Patsialou A. Chemotaxis in cancer. Nat Rev Cancer. 2011;11:573-87.

13. Garren M, Son K, Raina JB, Rusconi R, Menolascina F, Shapiro $\mathrm{OH}$, et al. A bacterial pathogen uses dimethylsulfoniopropionate as a cue to target heat-stressed corals. ISME J. 2014;8:999-1007.

14. Nyholm SV, Mcfall-Ngai MJ. The winnowing: establishing the squid-Vibrio symbiosis. Nat Rev Microbiol. 2004;2:632-42.

15. Tout J, Jeffries TC, Petrou K, Tyson GW, Webster NS, Garren M et al. Chemotaxis by natural populations of coral reef bacteria. ISME J. 2015;9:1764-77.

16. Broek AV, Vanderleyden J. The role of bacterial motility, chemotaxis, and attachment in bacteria plant interactions. Mol Plant Microbe In. 1995;8:800-10.

17. Kiers ET, Denison RF. Sanctions, cooperation, and the stability of plant-rhizosphere mutualisms. Annu Rev Ecol Evol S. 2008;39:215-36.

18. Nilsson M, Rasmussen U, Bergman B. Cyanobacterial chemotaxis to extracts of host and nonhost plants. FEMS Microbiol Ecol. 2006;55:382-90.

19. Sood SG. Chemotactic response of plant-growth-promoting bacteria towards roots of vesicular-arbuscular mycorrhizal tomato plants. FEMS Microbiol Ecol. 2003;45:219-27.

20. Haq IU,Zhang M,Yang P,van Elsas JD, The Interactions of Bacteria with Fungi in Soil. Adv Appl Microbiol. 2014;89:185-215.

21. Stopnisek N, Zuhlke D, Carlier A, Barberan A, Fierer N, Becher $\mathrm{D}$, et al. Molecular mechanisms underlying the close association between soil Burkholderia and fungi. ISME J. 2016;10:253-64.

22. Adl SM, Simpson AGB, Lane CE, Lukes J, Bass D, Bowser SS, et al. The revised classification of eukaryotes. J Eukaryot Microbiol. 2012;59:429-93.

23. Brock DA, Douglas TE, Queller DC, Strassmann JE. Primitive agriculture in a social amoeba. Nature. 2011;469:393-6.

24. Brock DA, Read S, Bozhchenko A, Queller DC, Strassmann JE. Social amoeba farmers carry defensive symbionts to protect and privatize their crops. Nat Commun. 2013;4:2385.

25. Amaro F, Wang W, Gilbert JA, Anderson OR, Shuman HA. Diverse protist grazers select for virulence-related traits in Legionella. ISME J. 2015;9:1607-18.

26. Greub G, Raoult D. Microorganisms resistant to free-living amoebae. Clin Microbiol Rev. 2004;17:413-33.

27. Schulz F, Lagkouvardos I, Wascher F, Aistleitner K, Kostanjsek $\mathrm{R}$, Horn M. Life in an unusual intracellular niche: a bacterial symbiont infecting the nucleus of amoebae. ISME J. 2014;8:1634-44.

28. Stallforth P, Brock DA, Cantley AM, Tian XJ, Queller DC, Strassmann JE, et al. A bacterial symbiont is converted from an inedible producer of beneficial molecules into food by a single mutation in the gacA gene. Proc Natl Acad Sci USA. 2013;110:14528-33.

29. Boscaro V, Kolisko M, Felletti M, Vannini C, Lynn DH, Keeling PJ. Parallel genome reduction in symbionts descended from closely related free-living bacteria. Nat Ecol \& Evol. 2017;1:1160-7.

30. Brock DA, Callison WE, Strassmann JE, Queller DC. Sentinel cells, symbiotic bacteria and toxin resistance in the social amoeba Dictyostelium discoideum. Proc Biol Sci. 2016;283:20152727.

31. DiSalvo S, Haselkorn TS, Bashir U, Jimenez D, Brock DA, Queller DC, et al. Burkholderia bacteria infectiously induce the proto-farming symbiosis of Dictyostelium amoebae and food bacteria. Proc Natl Acad Sci USA. 2015;112:E5029-37.

32. Dziallas C, Allgaier M, Monaghan MT, Grossart HP. Act together-implications of symbioses in aquatic ciliates. Front Microbiol. 2012;3:288.

33. Amin SA, Parker MS, Armbrust EV. Interactions between diatoms and bacteria. Microbiol Mol Biol R. 2012;76:667-84.

34. Martinez-Garcia M, Brazel D, Poulton NJ, Swan BK, Gomez ML, Masland D, et al. Unveiling in situ interactions between marine 
protists and bacteria through single cell sequencing. ISME J. 2012;6:703-7.

35. DiSalvo S, Brock DA, Smith J, Queller DC, Strassmann JE. In the social amoeba, Dictyostelium discoideum, density, not farming status, determines predatory success on unpalatable Escherichia coli. BMC Microbiol. 2014;14:328.

36. Kessin RH. Dictyostelium: Evolution, Cell Biology, and the Development of Multicellularity. Cambridge University Press; Cambridge. 2001; pp 1-6.

37. Sawana A, Adeolu M, Gupta RS. Molecular signatures and phylogenomic analysis of the genus Burkholderia: proposal for division of this genus into the emended genus Burkholderia containing pathogenic organisms and a new genus Paraburkholderia gen. nov harboring environmental species. Front. Genet. 2014;5:429.

38. Vandamme P, Peeters C, De Smet B, Price EP, Sarovich DS, Henry DA, et al. Comparative genomics of Burkholderia singularis sp nov., a low $\mathrm{G}$ plus $\mathrm{C}$ content, free-living bacterium that defies taxonomic dissection of the genus Burkholderia. Front. Microbiol. 2017;8:1679.

39. Ha DG, Kuchma SL, O'Toole GA. Plate-based assay for swimming motility in Pseudomonas aeruginosa. Methods Mol Biol. 2014a;1149:59-65.

40. Ha DG, Kuchma SL, O'Toole GA. Plate-based assay for swarming motility in Pseudomonas aeruginosa. Methods Mol Biol. 2014b;1149:67-72.

41. Caballero-Mellado J, Martinez-Aguilar L, Paredes-Valdez G, Santos PE. Burkholderia unamae sp. nov., an N2-fixing rhizospheric and endophytic species. Int $\mathrm{J}$ Syst Evol Microbiol. 2004;54:1165-72.

42. Perin L, Martinez-Aguilar L, Paredes-Valdez G, Baldani JI, Estrada-de los Santos P, Reis VM, et al. Burkholderia silvatlantica sp nov., a diazotrophic bacterium associated with sugar cane and maize. Int J Syst Evol Micr. 2006;56:1931-7.

43. Vandamme P, Goris J, Chen WM, de Vos P, Willems A. Burkholderia tuberum sp nov and Burkholderia phymatum sp nov., nodulate the roots of tropical legumes. Syst Appl Microbiol. 2002;25:507-12.

44. Mazumder R, Phelps TJ, Krieg NR, Benoit RE. Determining chemotactic responses by two subsurface microaerophiles using a simplified capillary assay method. J Microbiol Meth. 1999;37:255-63.

45. Gowda H, Ivanisevic J, Johnson CH, Kurczy ME, Benton HP, Rinehart D, et al. Interactive XCMS online: simplifying advanced metabolomic data processing and subsequent statistical analyses. Anal Chem. 2014;86:6931-9.

46. Smith CA, Want EJ, O'Maille G, Abagyan R, Siuzdak G. XCMS: processing mass spectrometry data for metabolite profiling using Nonlinear peak alignment, matching, and identification. Anal Chem. 2006;78:779-87.

47. Tautenhahn R, Patti GJ, Rinehart D, Siuzdak G. XCMS online: a web-based platform to process untargeted metabolomic data. Anal Chem. 2012;84:5035-9.

48. Bolker BM, Brooks ME, Clark CJ, Geange SW, Poulsen JR, Stevens MHH, et al. Generalized linear mixed models: a practical guide for ecology and evolution. Trends Ecol Evol. 2009;24:127-35.

49. Estrada-de los Santos P, Vinuesa P, Martinez-Aguilar L, Hirsch AM, Caballero-Mellado J. Phylogenetic analysis of Burkholderia species by multilocus sequence analysis. Curr Microbiol. 2013;67:51-60.

50. Huan T, Forsberg EM, Rinehart D, Johnson CH, Ivanisevic J, Benton HP, et al. Systems biology guided by XCMS Online metabolomics. Nat Meth. 2017;14:461-2.

51. Altschul SF, Madden TL, Schaffer AA, Zhang JH, Zhang Z, Miller W, et al. Gapped BLAST and PSI-BLAST: a new generation of protein database search programs. Nucleic Acids Res. 1997;25:3389-402.

52. Horai H, Arita M, Kanaya S, Nihei Y, Ikeda T, Suwa K, et al. MassBank: a public repository for sharing mass spectral data for life sciences. J Mass Spectrom. 2010;45:703-14.

53. Wishart DS, Jewison T, Guo AC, Wilson M, Knox C, Liu YF, et al. HMDB 3.0-The human metabolome database in 2013. Nucleic Acids Res. 2013;41:D801-7.

54. Smith CA, O'Maille G, Want EJ, Qin C, Trauger SA, Brandon TR, et al. METLIN - a metabolite mass spectral database. Ther Drug Monit. 2005;27:747-51.

55. Elliott GN, Chou JH, Chen WM, Bloemberg GV, Bontemps C, Martinez-Romero E, et al. Burkholderia spp. are the most competitive symbionts of Mimosa, particularly under N-limited conditions. Environ Microbiol. 2009;11:762-78.

56. Garcia JR, Laughton AM, Malik Z, Parker BJ, Trincot C, Chiang SSL, et al. Partner associations across sympatric broad-headed bug species and their environmentally acquired bacterial symbionts. Mol Ecol. 2014;23:1333-47.

57. Kikuchi Y, Meng XY, Fukatsu T. Gut symbiotic bacteria of the genus Burkholderia in the broad-headed bugs Riptortus clavatus and Leptocorisa chinensis (Heteroptera: Alydidae). Appl Environ Microb. 2005;71:4035-43.

58. Pandya S, Iyer P, Gaitonde V, Parekh T, Desai A. Chemotaxis of rhizobium SP.S2 towards Cajanus cajan root exudate and its major components. Curr Microbiol. 1999;38:205-9.

59. Daniel JW, Gage JC, Jones DI. The metabolism of 3,5-di-tert.butyl-4-hydroxytoluene in the rat and in man. Biochem $\mathrm{J}$. 1968;106:783-90.

60. Yamamoto K, Tajima K, Takemura M, Mizutani T. Further metabolism of 3,5-Di-Tert-Butyl-4-Hydroxybenzoic acid, a major metabolite of butylated hydroxytoluene, in rats. Chem Pharm Bull. 1991;39:512-4.

61. Dey TB, Chakraborty S, Jain KK, Sharma A, Kuhad RC. Antioxidant phenolics and their microbial production by submerged and solid state fermentation process: A review. Trends Food Sci Tech. 2016;53:60-74.

62. Babu B, Wu JT. Production of natural butylated hydroxytoluene as an antioxidant by freshwater phytoplankton. J Phycol. 2008;44:1447-54.

63. Barnett R, Stallforth P. Natural products from social amoebae. Chemistry. 2018;24:4202-14.

64. Hoffmann C, Harrison CF, Hilbi H. The natural alternative: protozoa as cellular models for Legionella infection. Cell Microbiol. 2014; $16: 15-26$.

65. Horn M, Wagner M. Bacterial endosymbionts of free-living amoebae. J Eukaryot Microbiol. 2004;51:509-14.

66. Tosetti N, Croxatto A, Greub G. Amoebae as a tool to isolate new bacterial species, to discover new virulence factors and to study the host-pathogen interactions. Microb Pathog. 2014;77:125-30.

67. Casadevall A. Evolution of Intracellular Pathogens. Annu Rev Microbiol. 2008;62:19-33.

68. McFall-Ngai M, Hadfield MG, Bosch TCG, Carey HV, DomazetLoso T, Douglas AE, et al. Animals in a bacterial world, a new imperative for the life sciences. Proc Natl Acad Sci USA. 2013;110:3229-36.

69. Strassmann JE, Shu L. Ancient bacteria-amoeba relationships and pathogenic animal bacteria. PLoS Biol. 2017;15:e2002460.

70. Kim J, Kang Y, Choi O, Jeong Y, Jeong JE, Lim JY, et al. Regulation of polar flagellum genes is mediated by quorum sensing and FlhDC in Burkholderia glumae. Mol Microbiol. 2007;64:165-79.

71. Kumar S, Vikram S, Raghava GPS. Genome annotation of Burkholderia sp SJ98 with special focus on chemotaxis genes. PloS ONE. 2013;8:e70624. 
72. Angus AA, Agapakis CM, Fong S, Yerrapragada S, Estrada-de los Santos P, Yang P, et al. Plant-associated symbiotic Burkholderia species lack hallmark strategies required in mammalian pathogenesis. PloS ONE. 2014;9:e83779

73. Schiestl FP, Johnson SD. Pollinator-mediated evolution of floral signals. Trends Ecol Evol. 2013;28:307-15.
74. Brock DA, Hubert AM, Noh S, DiSalvo S, Geist KS, Haselkorn TS, et al. Endosymbiotic adaptations in three new bacterial species associated with Dictyostelium discoideum: Burkholderia agricolaris sp. nov., Burkholderia hayleyella sp. nov., and Burkholderia bonniea sp. nov. BioRxiv. 2018;304352. 